\title{
Conservation and revitalisation of historic streets in China: Pingjiang Street, Suzhou
}

\begin{abstract}
A New Life for China's Historic Streets
The excessive assimilations of modern and 'foreign' urban landscapes in China have been rapid and often uncontrolled resulting in, as with many Asian contexts, transformed "...urban areas and their settings, [causing] fragmentation and deterioration to urban heritage" (UNESCO, 2011). In parallel, however, historical and cultural-led urban development evidenced by the preservation and rebuilding of historical forms, has become a modern phenomena. Almost every Chinese city is striving to be competitive and attractive, for economic and political reasons, and one common strategy is to revitalise the local areas and economy through historical and cultural-led urban redevelopment. This has led to architects and urban planners playing an increasingly major role in urban conservation practice in China. Notably, there was a shift in the scale of conservation projects, from single buildings to larger urban areas, during the 1980s (Ruan, 2005: 3137; Whitehand \& Gu, 2007: 643-650), due to the rapid urbanisation process and a reawakening awareness of place-based heritage value.
\end{abstract}

Significantly, particularly in the context of urbanisation in China, UNESCO (undated) suggest that: "Heritage constitutes a source of identity and cohesion for communities disrupted by bewildering change...". Unfortunately, however, the result has been that many decayed historical urban environments have been transformed into 'chic places' with questionable authenticity often under the official banner of historical and/or cultural conservation. All over China, there are many such examples of famous regenerated historic streets/districts, predominantly catering for tourists, such as Liulichang, Qianmen, and Nanluoguxiang in Beijing, Xintiandi in Shanghai, Kuanzhaixiangzi in Chengdu, and so on. These projects have all been initiated by local governments, usually in partnership with the private developers to transform an otherwise decaying urban fabric into commercial places with a historical flavour.

Whitehand and Gu (2007: 643) suggest that there has been limited research on Chinese urban conservation, particularly from historical, methodological and theoretical perspectives. Indeed, although topics related to urban heritage conservation have received increasing attention, and relevant scholarship is prolific in Chinese (e.g. Collection of International Symposium on Conservation of Historical Cities and Buildings, 2006; Urban Heritage Conservation, 2010), they tend to be dictated by Western theories, and often lack a systematic approach.

\section{The Role of Authenticity in Townscape Conservation}

If heritage is a valuable asset that we can extract from the past and bring forward to the future, there is a vexed question in heritage conservation practice regarding the moral and aesthetic 'authenticity' of reviving historic fabrics. Arguably, the modern notion of authenticity on conservation practice goes back to the 1972 World Heritage Convention, 
which defined authenticity as the primary and essential condition of the heritage. UNESCO (2009: 7) further state that: "Authenticity is usually understood in terms of a matrix of dimensions of authenticity: of location and setting; form; materials and design; use and function; and "immaterial" or essential qualities. Together these form the composite authenticity from which significance derives. The retention of authenticity is the aim of good conservation practice." The issue of authenticity is an on-going topic of debate and pervades conservation theory and practice across all disciplines. In relation to heritage conservation, the Nara Conference of 1994 and the resulting Nara Document on Authenticity (Japan Agency for Cultural Affairs et al., 1994) advanced the discussion, and broadened the issue and understanding of authenticity and provided guidance on reconciling conservation practice.

In simple terms, achieving a successful conservation project lies essentially in how much we understand and effectively engage with our past. Whilst many authoritative bodies such as ICOMOS $(2003 ; 2005)$ and UNESCO $(2009 ; 2011)$ identify the importance of safeguarding the intangible aspects of urban heritage in Asian cities, including the physical, cultural and societal dimensions, few discuss the sometimes-subjective nature of the decision-making. Indeed, whilst authenticity within architectural conservation often refers to the notion of originality, through the articulation of what is original and what is respectful or creative restoration, in heritage-led urban conservation, authenticity extends to a much broader range of aspects. As such, the notion of authenticity within urban settings covers physical, social, economic and environmental perspectives (e.g. history, culture, politics, health, ecology, etc.) there are more value judgements to be made in determining an appropriate and sensitive route towards conservation.

The case study of Pingjiang Street in Suzhou analysed in this paper, rather than offering a critical assessment of western-inspired assimilation processes, investigates the historical value embedded in the traditional Chinese urban fabric, in order to provide a new interpretation of 'authenticity' that can shed light on the current urban design practice of conservation in China.

\section{Urban Conservation and Revitalisation in China}

Influenced by the western practice of heritage conservation, in 1982, the Chinese State Council approved the Permission for Conservation of Historical and Cultural Famous Cities in China initiated by the State Infrastructure Commission, the Bureau of Cultural Relics, and the Bureau of City Construction. After a visit to Western Europe led by a Chinese delegation of heritage officials and professionals, 24 cities were thus registered as the first cohort of 'historical-cultural famous cities' that had significant historical value (Zhang, 2008: 6; Qian, 2007: 256-257). This marked a turning point, in that urban conservation, though the notion remained unclear at that time, gained significant importance on the political agenda and therefore received renewed interest. The Law of Cultural Relic Protection defined the selection criteria for a 'historical-cultural city' loosely as "...cities that have reserved abundant cultural relics, assuming important historical value and revolutionary meanings." (Zhang, 2008: 8) Tellingly, this Law still placed importance on individual buildings rather than larger urban areas (Ruan, 2005: 38). In 1985, the concept of the 'historical traditional street district' was introduced by the Ministry of Construction and subsequently adopted by the State Council to identify different local historical- 
cultural zones for conservation. Accordingly, a second list of 38 cities was formulated in 1986 and another 37 cities were added in 1994. By 2007, there were total 109 cities qualifying for the title of 'historical and cultural city' and the number of cities on the list further increased to 125 in 2014.

In 1994, the Ministry of Construction and the Bureau of Cultural Relics formulated the Guideline for Preparing Conservation Plans for Famous Historical-Cultural Cities, which emphasised an area-based strategy of planning, focusing on the historical street/districts and their surrounding physical environment. Then in 2005, after ten years of practice and theoretical influence from the West, the Ministry of Construction enacted the Regulation of Conservation Plans for Famous Historical-Cultural Cities, in which both the content and objective of conservation became more explicit. Indeed, the Regulation classified three categories of conservation: the city; the street/district; and individual structures. In addition, a number of relevant strategies were articulated, including: the demarcation of boundaries; the height control of architecture; street traffic; civil engineering; hazard prevention; and environmental protection. Even nuanced terms, such as conservation, preservation, refurbishment, improvement, repair, and rehabilitation, were briefly defined (Ministry of Construction, 2005). Proposed projects, often prepared collaboratively by design institutes, local government, and private developers, subsequently had to incorporate all of the guidelines of the Regulation in order to achieve approval. However, being integral to the development of urban planning in China, methods of urban conservation were derived principally from land-use planning (Whitehand \& Gu, 2007: 648-9). As such, the formulation and implementation of urban conservation plans, exhibited a 'top-down' government approach, in which the independence of the heritage profession and the applicability of those planning principles were doubtful (Qian, 2007). The joint initiation and ownership of the conservation guidelines by the aforementioned state departments also led to the production of various and often overlapping plans subjected to the approval of different government authorities. As such, there were a number of key criticisms of China's urban conservation planning such as it being unsystematic, ambiguous in its targets, confusing in the definition of its area, and commonly experiencing conflicts between relevant controlling departments (Liu \& Wan, 2006: 24-28).

The practice of urban renewal or urban regeneration in China followed a different trend compared to the West due to its unique political and economic circumstances. Indeed, every Chinese municipal government has been striving to boost local fiscal revenue through huge capital investments in infrastructure and urban renewal projects with the purpose of increasing the land's value for sale (lease). In this sense, the local government becomes the de facto developer in initiating massive scale urban projects. Unfortunately, this has often led to a common practice in urban renewal/regeneration whereby much historical urban fabric has been entirely removed for new development to maximise profits. The notion and practice of 'old city renewal' (jiucheng gaizao, a Chinese term of urban renewal, which essentially means a radical redevelopment) is much criticised as a violation against heritage (Zhang, 2006: 67). Fan (2014) also suggests that most urban heritage conservation projects fail to assume a genuine sense of revitalisation due to a lack of community involvement or local community-oriented regeneration. Indeed, Xintiandi in Shanghai exemplifies many urban conservation projects. Here, the complete 
rebuilding and the simple copying of historic forms and decoration together with the total removal of local inhabitants has transformed a decayed urban fabric into a chic touristoriented place. Significantly, these examples of urban gentrification typically led to the displacement of the actual living patterns of local residents and therefore much of the essence of the place (Smith, 2002).

Planning terms such as urban conservation, renewal, or regeneration, revitalisation are interchangeably practiced in China, and typically the main intent has been to initiate a redevelopment project for the economic gain and political achievement of the local government. As such, these redevelopment-led urban renewal activities, have posed tremendous challenges to the conservation of physical and socio-cultural environments in Chinese historical cities (Zhai \& Ng, 2013:16). Following China joining the United Nations Educational, Scientific and Cultural Organization (UNESCO) in 1985, 47 Chinese sites had appeared on the World Heritage List by 2014, despite the numerous conservation projects aiming for UNESCO's entitlement. Nevertheless, the desirable status of the World Heritage List amongst Chinese local governments has affected local conservation policies, which adopted "...a tendency towards western conservation philosophy, especially in the treatment of the originality of the fabric of heritage sites." (Qian, 2007: 263). In addition, following the massive production of 'fake' historical structures and sites mainly serving commercial and tourism purposes, the notion of 'authenticity' in relation to heritage conservation has been placed on agenda and become a primary principle guiding conservation practice. In the Principles for the Conservation of Heritage Sites in China (2000), authenticity is interpreted as a historic condition, referring to the original condition of a site and its subsequent changes through historical time (Zhu, 2015: 5; ICOMOS China 2002). This is reflected in the common conservation practice of "...repairing the old to appear old [as opposed to repairing it to look new]." (Xiujiu Rujiu, translated by Berliner, 2005: 214).

Many teaching staff (often registered architects and urban planners) from architecture and urban planning schools in China are actively involved in conservation practice, undertaking research to theoretically explore the relevant polices (Zhang, 2008; Zhang and Zhou, 2010; Shan and Ruan, 2010) and the notion of authenticity (Dai, et al, 2006; Ruan and Lin, 2010; Lu, 2010). In China, two opposing yet influential schools of thought from Europe related to conservation have also been critically reviewed: the antiinterventionist by John Ruskin and William Morris advocating originality; and the interventionist by Eugène Viollet-le-Duc that proposes creative restoration. In addition, a synthesized subtle combination of the above approaches by Camillo Boito, together with a complex multi-layered evaluation system towards historical monuments espoused by Alois Riegl (Lu, 2010: 62-70). This demonstrates a maturing attitude towards architectural conservation in China, however, there is still an outstanding issue regarding larger urban areas, as too often, the geographical relationship between new buildings and the historical grain and orientation of traditional units has been ignored (Whitehand et al. 2011: 183). Whitehand et al. (2011) thus advocate the Conzenian approach, namely urban morphological analysis and synthesis, in designing and managing Chinese urban townscapes. Similarly, Chen and Thwaites (2013) propose a typomorphological approach to Chinese urban design. 
Despite the renewed interest in urban heritage conservation in China its practice is still maturing slowly. Indeed, practice and theory of urban conservation in China is still overwhelmingly influenced by the western traditions and approaches, placing significant importance on theoretical or mythological applicability between the West and China. Often this results in only cursory inquiry regarding the rich historical experience embedded in those historical artefacts. Through the description and analysis of the history and people's living patterns of Pingjiang Street in Suzhou, this research attempts to find a culturally-rooted response to authenticity within contemporary urban conservation and revitalisation projects in China.

\section{History and Evolution of Pingjiang Street, Suzhou}

Suzhou is a historic city in Jiangsu Province that is famous for its historic waterways, architecture and gardens. The city was built for the state of Wu around $514 \mathrm{BC}$ and has undergone many periods of restoration and redevelopment, however, the urban fabric largely remained intact until the mid-19th century (Xu, 2000: 128-129). From the Northern Song dynasty to the end of the Yuan dynasty (1113 to 1367), Suzhou became a prefecture seat respectively known as Pingjiang Fu and Pingjian Lu (Dong, 2004: 11). It is likely that Pingjiang Street also obtained its name around this time and it is now one of Suzhou's most famous historic streets/districts (see Figure 1). The following sections will, through a dialectical discourse, examine the socio-cultural factors that have shaped Pingjiang Street to enable a better understanding and assessment of heritage-led urban revitalisation projects in China. It will trace the history and evolution of this unique historic street, interpret its physical attributes, outline its periods of transition and threats to its future, and conclude by examining the strategies, policies and practice of conservation and revitalisation in recent years.

The long history of the Pingjiang district can be broadly considered in two critical phases: firstly, its incremental development and evolution during the Imperial period; and secondly, the more turbulent period of development pressure and change in the twentieth century through to its conservation in the early 2000s. Remarkably, the urban pattern of the historic district Pingjiang district is well preserved and can be traced back to the Song dynasty when a famous map of the city, Pingjiang tu, was carved on stone in $1229 \mathrm{by} \mathrm{Lv}$ Ting, Zhang Yuncheng, and Zhang Yundi (Wang, 1999:1). The map faithfully reflected the urban fabric of Suzhou in Southern Song times and is acclaimed as a masterpiece of imperial Chinese urban planning (see Figure 2). Despite having this formal planning history, the layout of Suzhou was also circumstantial in that it was mainly dictated by the numerous waterways that crossed the city. Pingjiang Street is located at the north-east sector of the old walled city and is about 1600 metres in length running parallel to the Pingjiang River to which it is connected by many small alleyways. Together, the streets and waterways created the traffic system of the whole city and are typical of this area of China. Indeed, a line in a poem "...small bridges, streaming waterways, houses" by famous Yuan scholar Ma Zhiyuan (1964: 242) epitomises a generic picture of these lively and prosperous farming and fishing neighbourhoods south of the Yangzi River. 
In Imperial Suzhou, many streets, bridges, and wards were named after local influential figures or households. The impact from those powerful or inspirational characters to the neighbourhood has great historical significance. For example, Baikou Alley (meaning alley of a hundred residents), which is the north extension of Piangjiang Street, was named after Baikou Bridge (bridge of a hundred residents) (Wang, 1986: 232). In its vicinity lived Gu Xun's family from the Eastern Han dynasty, where five generations of a hundred family members all lived together in the same household. Among the family members, there was equality in the distribution of clothes and food, yet the domestic order of superiority and inferiority was clearly drawn (Fan, 1999: 236). Therefore, the community took Gu's household as an exemplar, and reached a consensus to build a bridge in the family's honour to commend their prosperity, filial piety and moral righteousness (Lu, 1999: 85). Whether the intent of construction was reflected in literary text or in a physical structure, it was nonetheless a form of pursuing monumentality. Indeed, perhaps the pre-modern Chinese were acutely aware of the vicissitudinous and unpredictable life of buildings. Even historically, the lifespan of a courtyard house much like a human life was seen as being a fleeting and limited period of time. To perpetuate the legend, the embodiment of social meanings was therefore often transferred to neighbouring streets or bridges through the attribution of the names of locals to key places or through textual representation. This was observed by Mote (1973: 51) in his writings about old Suzhou, whereby he recognised that: "Chinese civilization seems not to have regarded its history as violated or abused when the historic monuments collapsed or burned, as long as those could be replaced or restored, and their functions regained... The real past of Soochow [Suzhou] is a past of the mind; its imperishable elements are moments of human experience. The only truly enduring embodiments of the eternal human moments are the literary ones."

In contrast to the individual homes, the physical elements of the urban structure, such as the streets and bridges, were seen as more enduring places to reflect human experience. The social value that once resided in an individual structure (house or building), therefore, had additional manifestations (street, bridge, district, etc.) upheld and shared by a larger community and thereby becoming imperishable. This was a common occurrence in Suzhou, where many bridges, streets, and districts are named after well-known people or households. Song dynasty scholar Fan Chengda (1999: 236) highlights this phenomenon: "At its most glorious days, Wu [Suzhou] is the place for gentlemen; the local people are sincere and magnanimous, and senior people are treated in respectful and favourable manner. The precedent officials of Wu are mostly famous figures, yet they would follow and accomplish the local custom. All the streets have signs indicating the names of the wards. For those scholars who are reputed for their moral excellence, the wards and streets where their residences located are often named after them... this custom is uniquely evident in the Wu region." Such literary works have informed contemporary conservation practice in Suzhou reflecting the modern notion 'story-scape' in historic preservation (Kaufman, 2009). Indeed, a goal of conservation has been to preserve such significant histories by ensuring that all interventions respect authenticity in all aspects including as in this case a critical invisible layer that contributes to social cultural capital and the identity of the neighbourhood.

The custom of naming key places in the city can be traced back to the Tang dynasty, when no household except the highest officials' homes were allowed to have a private gate onto 
the main street (Wang, 1955: 1576). This endowed these households with the privilege to freely access the main street without passing through the guarded ward gates. Such houses were called $d i$ (residence of a high official), suggesting a prestigious social status obtained through a direct engagement with the street (i.e. the public space) (Yang, 1993: 216-217). This was, however, often more related to honouring a particular household by naming a street after them. One noteworthy newspaper picture of Suzhou society from the late Qing dynasty (1884-1898) depicted a benevolent scene at the front street of Pan Zengyi's mansion with "...dozens of poor people lining up at the front gate to receive free clothes and shoes, food and rice, and even silver money" (Wang, 2003: 98) (see Figure 3). Importantly, the alley bore the imprint of one's household name not due to their wealth or socio-political position, but because of their philanthropic gestures.

Xu (2000: 128-129) points out that Suzhou was one of the first cities to embrace a profound change in its spatial organisation (i.e. the disappearance of the enclosed marketplace and the walled ward system) between the eighth and twelfth centuries. In addition to a conventional city layout, the canal system in Suzhou played an essential role in facilitating this change and shaping the physical structure of the city. The waterways were not only appropriated for traffic but also served as spatial dividers that formed the residential blocks. In their studies of the urban planning of Suzhou in Song times, Yu (1980) and Johnston (1983) respectively illustrate a typical residential block in the Pingjiang district of Suzhou. The urban ward with a total length of 500 metres contained twelve residential plots each with a fixed depth of 150 metres and varying widths from 30 to 70 metres (see Figure 4). Each of the dwellings was a courtyard house, with its own gated entrance that together formed a large walled urban block. The housing plots were set in an ideal south-north direction whilst the arterial streets and waterways, such as Pingjiang Street and Pingjiang River, in this direction had less interaction with the houses. In contrast, the alleys and waterways with east-west orientation had direct access gates to the households.

In his seminal book Song Pingjiang cheng Fang kao, written in the early $20^{\text {th }}$ century, Wang Jian (1999: 205) surveyed all the literature from the Song to the Qing dynasties regarding the historical geography of Pingjiang district, but disappointingly concluded that "Pingjiang Street has no specific record." There are three ancient wells still remaining in the street and according to an old custom from the Song dynasty, either the building or repairing of a well in Suzhou was often associated with a series of literary writings as part of the ceremonies to celebrate their existence. Qing scholar Gu Zhengtao (1999: 55) recorded in Wumen biaoyin that "Pingjiang Street in ancient times was called Shi Quan Li [Shi Quan means Ten Springs, and li is a basic neighbourhood administration unit], because there were ten ancient wells." This also indicates that Piangjiang Street was not being personified by any single household but served as a public place or amenity for the community in Imperial times.

\section{Rich Tapestry of Streets and Courtyard Houses}

In historic Chinese cities, the relationship of street and houses are important not just in a physical sense but even more so in terms of the social order that they establish and the 
meanings of their co-existence. In the planning precepts from imperial China, streets were underlined as a key element constituting a city, while little consideration was given to houses as they were the products of individual actions. The reality, however, as in Pingjiang Street, is that it is the houses (i.e. the buildings flanking the street) and their households that articulate the physical and perceptual forms of the streets.

In Suzhou, the courtyard house of the Pan family in Pingjiang district was the largest and richest household in the city during the mid-Qing dynasty (1759-1841). Their well preserved housing complex is located on Weidaoguanqian Alley connecting to Piangjiang Street. The small alley was named after the Daoist temple Weidao Guan and originally built at the beginning of the Yuan dynasty. There used be a waterway 300 metres long next to the alley, but it was filled and levelled in the early Qing dynasty for housing development. In the courtyard house of Pan family complex there were five axial routes and along each route there were six or seven layers of courtyard-building clusters, ranging from south to north these were: the gate house; palanquin hall; main hall; lofty hall; and inner hall on a total land area of 9613 square metres (Xu, 2011: 16) (see figure 5). In 1721, the Wu merchant Pan Linzhao moved his house to Weidaoguanqian Alley and on his deathbed he requested that his three sons "... establish our ancestral temple and purchase farmland for raising the poor, ...however, so far I have only a few hectares of farmland, and only one piece of land for our residence that is insufficient for living. I hope you would make great efforts." (Xu, 2011: 17-19). By 1783, the Pan family had spent around 30,000 liang silver (ancient money equivalent to about 1,500 kilograms of silver) to rebuild and extend their houses on Weidaoguanqian Alley (see Figure 6). The Pan family's completed housing complex is a typical residential block, that absorbed a number of neighbouring residential dwellings whilst retaining the courtyard pattern connected to the adjoining streets or waterways. Such cases were abundant, particularly in Pingjiang district, where the waterways and streets shaped the scale of an urban block, creating a modular juxtaposition of courtyard houses, for example, the scholar-official Pan's mansion at Niujia Alley, the scholar-official Hong's mansion at Xuanqiao Alley, the gentry Pang's mansion at Daxinqiao Alley (SREAB, 2004). No matter how many axial routes those households contained, there was always a clear and universal spatial structure on each single route, in particular the central route from the front street to the rear street or waterway.

The front facades to the street were generally plain, solid walls with minimal openings, except for a decorative gate that was often framed by a brick-carving inscribed with a title of the household and indicating its social standing (SREAB, 2004). Johnston (1983: 210) notes how in the Song dynasty, the important houses of Suzhou had a screen or spirit wall placed opposite the entrance and often against the edge of the waterway "...to delimit the position of the entrance to a house and thus control the area in front of the house." This practice is also associated with achieving a strong feng shui for the house as the street to the front of a preeminent household was a social place where it could assert its power to the community, not only through physical display but also more importantly, by the actual demeanour of the household. Indeed, Bray (1997: 93) identifies that the gate of a traditional courtyard house was not simply a physical barrier, but "...was used to communicate family events to the surrounding community." The front street of a courtyard house was also a social arena, particularly for scholarly families, where Confusion virtue 
would be exercised and revealed to the public. At the rear of the house, there was either a boundary wall or a garden, and if there was a waterway, then stone steps or a wharf would be built leading into the water to act as both a functional and recreational place (see figure 7). To a certain extent the waterways in Suzhou assumed a more important position than the streets during the Imperial period as large quantities of goods were shipped from countryside into the city and sales would occur on the wharfs or even directly through the windows of the households. The residents would also wash their clothes and vegetables at the wharfs and children would play in the water. In a sense, the waterways and the houses were seamlessly connected as an indispensible part of domestic life and organic extension of the house.

All of the large courtyard houses in the Pingjiang district exhibited a universal layout of highly regulated and compartmentalised spaces. Significantly, the layout of the courtyard houses was adopted by many institutional buildings, such as temples, schools, government compounds, restaurants, guildhalls and even theatres, throughout the Imperial period. This was particularly evident in Suzhou and the city's biography Wudi Ji, first published in the Tang dynasty, showed that many religious places were actually converted from private houses (see Lu, 1999). The adaptability of this residential typology is also demonstrated by the Xi Zhu Temple in Pingquan ward, which was converted from Ma Hou's private house in 854. Subsequently, the temple was occupied by Buddhist nuns, and then in 943, it was changed by the Qian family to an alms-house, named Baoshou Yuan (courtyard for maintaining longevity). Change and adaptation of the former residential complex continued in the early Ming dynasty (1368-1644) when it was restored as a monastery, which in turn was abandoned in the 1520 s, and shortly after converted back to a private residence by the court official Hu Zanzong (Lu, 1999: 127). These changes, particularly from private house to public institutional building, often largely retained the layout, yet progressively advanced the relationship between the building and the street.

The courtyard house and its associated the streets (or waterways) could be considered as a miniature society and cosmos where Confucian ideology towards domestic life and public sphere were evident. It is well acknowledged that courtyard house of pre-modern China, catered for an extended family or a social group and functioned as a spatial apparatus performing and regulating domestic and social orders with its organisation of different people and behaviours into different spaces. Indeed, Jervis (2005: 228) notes that family relationships were "...expressed in the placement of individual rooms and pathways in addition to the actual relationships between and among rooms and pathways." The courtyard house was also a self-sufficient domain, where conformity and contradiction, discipline and indiscipline, moral and natural order, human and the divine, all intertwined. In addition, as evidenced by the names of the streets, bridges, and wards in Suzhou, it is clear that the scholar-officials and morally righteous residents were at the centre of the neighbourhood. As a whole, both courtyard houses and streets organically constituted the urban form that embodied a common value of Confucianism. Many have observed that there was a stagnation of architectural development in pre-modern China due to the repetitive use of courtyard houses. This, however, fails to recognise the adaptability and resilience of the courtyard house typology as the embodiment of the social system. Indeed, Bray (1997: 2) identifies that: "Despite wars and invasions, natural 
disasters, dramatic population changes and economic growth, the social system in China between A.D. 1000 and 1800 displayed remarkable continuity." This continuity clearly left the imprint on the urban fabric of Piangjiang district in Suzhou.

\section{Periods of Disruption, Transition and Threat}

From the mid-19th century onwards, urban areas in China witnessed a tortuous history through until the 1980s, when the People's Republic shifted its political focus towards modernisation and economic development. During the intervening period, the city of Suzhou had experienced catastrophic changes in its urban form and life. In 1851 the Taiping Rebellion began and nine years later the rebellion army defeated the Qing defences in Suzhou leading to numerous deaths and many inhabitants fleeing the city. During the retreat, the Qing army burned many buildings in Suzhou including the whole commercial district (Pan, undated: 1). In November 1863, the 'Ever-Victorious Army', an Imperial army led by the British commander Charles Gordon recaptured the city from the Taiping forces, but again this resulted in widespread damage to the urban fabric. After the signing of the Treaty of Shimonoseki in 1895 that ended the First Sino-Japanese War, Suzhou was designated as one of the treaty ports and became a concession area occupied by the Japanese, British, and Americans. This period led to many foreign enterprises such as trading companies, schools, churches and hospitals being established inside the city (SDFZB, 2014).

In 1911, the famous Xinhai Revolution overthrew China's last Imperial dynasty, the Qing dynasty, and established the Republic of China. On the $5^{\text {th }}$ November 1911, the independence of Suzhou was announced with the support of the Suzhou gentry who wished to avoid further war. The Japanese invasion (1937-1945) further led to significant air raids on Suzhou between August and November 1937 with nearly 5000 houses in the old city area being destroyed (Xiaotian, 1999: 171). Suzhou remained severely damaged throughout the Civil War period and into the early period of the People's Republic of China, following its formation in 1949. Further physical damage to the historic city occurred as a result of the Communist Party's Great Leap Forward from 1958 to 1961. During this period, the majority of the old city walls were demolished with the bricks being appropriated for other uses. At this time many of the city's historic courtyard houses were converted to factories, whose proportion of the whole city area increased from 3.6 per cent in 1949 to 25 per cent at the end of 1950s (Chen, 2006: 102).

In Pingjiang district, many of the courtyard houses, including the Qing merchants Pan family home, were confiscated by the central government in the 1950s under the Land Reform Law on June 30 1950. The ownership of the homes was then redistributed to landless peasants and owners of small plots leading to most courtyard houses being occupied by multiple households in crowded squalid conditions (Xu, 2011: 139). Significant additional damage to the unique historic townscape came in 1958 when a central government campaign to eliminate mosquitoes, flies, mice and cockroaches led to twelve waterways in Suzhou being filled and levelled. In addition, the 1970s saw many of Suzhou's waterways being utilised for the construction of air-raid shelters that damaged the water system and caused serious pollution. As a result, by 1985 there had been 23 waterways at a total length of 16,317 kilometres filled in. The Cultural Revolution 
between 1966 and 1976 also resulted in crucial damage to the historical heritage with many historical sites, relics, classical gardens, large courtyard houses, temples, and monasteries being destroyed.

\section{Strategy and Policy for Conservation and Revitalisation}

For historic conservation, the Third Plenary Session of the 11th Central Committee in December 1978 was a particularly significant moment in Chinese modern history. This signalled a shift in the Party's work and moved the focus to socialist modernisation. In Suzhou, this led to increased attention towards the preservation of its historic urban fabric and in 1986, the first overall Urban Plan of Suzhou (1985-2000) was approved by the State Council. In the Plan, the Pingjiang district, as a major residential area of Suzhou dating back to the Song dynasty, was marked as an absolute preservation zone because of its typical urban courtyard block pattern with houses connected to the street at the front and the river at the back. The long-term plan was to gradually restore the area to an ancient, beautiful historical site that reflects the key feature of a water country and a 'Song city' (Yu, 1986: 10).

In 1988, the city's urban construction department invited a number of 'first-class' domestic universities and planning institutes to work on the urban planning for seven selected streets/districts, including the Pingiiang street. Overall, the planning methodology towards Pingjiang district was to keep the current urban morphology while fulfiling the needs of modern living (Ruan and Xiang, 1997). A conference, led by Pei Partnership Architects and EDAW, focusing on the planning of the Pingjiang district was held in July 1996 which led to the submission of a conservation planning proposal. Then in 1997, Tongji University were commissioned to formulate the planning document for Pingjiang district under the leadership of Professor Ruan Yisan, an eminent urban planning expert in China who had been involved in many historical town planning and preservation projects (Xia and Ma, 2009: 23). More detailed planning and specific renovation in the Pingjiang district was undertaken in 2002 leading to a new urban plan for Suzhou in 2003 that focused on historical and cultural conservation. This new plan designated the revised conservation area of Pingjiang district as 30.66 hectares (Leng, 2013: 20). In 2004, Suzhou hosted the 28th World Heritage Committee and in preparation for the event the municipal government initiated a trial project for the preservation and renovation of the Pingjiang district. A planning document Conservation and Restoration Plan of Suzhou Pingjiang Historical and Cultural Street/District of the Old Suzhou was prepared by the same team from Tongji University and this further expanded the conservation area to 116.5 hectares (Leng, 2013: 20) (see figure 8). The first phase of the Pingjiang conservation and restoration project with an area of 32,000 square metres and a total cost of \$5,179,000 was completed in May 2004 (UNESCO, 2005; Xia and Ma, 2009). The planning and construction works focused on four key dimensions:

(i) the restoration of the appearance of the traditional architecture, categorised into different approaches including repairs, alterations, maintenance, renovation, renewal and selective demolition for the 475 households and units listed in the area;

(ii) the infrastructure and amenities of the area were improved including sewage, electricity, water, gas, telecommunications, and street lights. In addition, 
public lavatories were constructed and individual bathrooms were installed for each household;

(iii) the visual and traffic qualities of Piangjian Street and Piangjian River were also improved to respect "...the aesthetic principles of primitive simplicity, beauty, freshness, and smoothness." The focus was on the street and river elevations and the public spaces; and

(iv) the water of the Pingjiang River was cleaned and the stone steps and wharfs were restored to encourage tourism activities (Ruan et al., 2010: 106).

At the same time, the city government sponsored two books that offered different perspectives whilst promoting the qualities of the Pingjiang District: Ancient City of Suzhou Pingjiang Historical Street (Yuan, 2004) and District and Ancient Aroma and Modern Atmosphere of Pingjiang Street (Fang, 2004). These books highlighted the intangible aspects of urban life in the Pingjiang district and were central to a bid to UNESCO for a world heritage award leading to the District being awarded an Honourable Mention of Asia-Pacific heritage site in 2005 (UNESCO, 2005). In 2009, Pingjiang Street was also listed in the top ten "...famous historical and cultural streets of China" by the China Culture Newspaper and China Relic Newspaper under permission from the Ministry of Culture and the State Administration of Cultural Heritage (RCCHSS committee, 2009: 236). A year later in 2010, the Pingjiang District was awarded 4A-class tourism status by the National Tourism Administration and it had become a highly popular destination for local, national and international tourists (see figure 9).

\section{Renovating the traditional courtyard dwellings}

Many of the courtyard homes of former famous households previously mentioned have now been renovated and a number of these have been sensitively adapted and reused as commercial premises, museums, and hotels. For example, the Mingtang Youth Hostel at 24-30 Pingjiang Street, the Higher Hotel at 66 Pingjiang Street, and Pingjiang Lodge accessed from 33 Niujiang Alley. Similarly, the scholar-officials Pan family's mansion has been converted to the luxury Huajian Tang hotel. Even the Pan family's merchants home has been renovated and is now a bookshop and teahouse (Figure 10). Other large courtyard houses have been converted to art and cultural places, for example, the Ding family's mansion that used to be at 6 Daru Alley has been rebuilt at 54 Daru Alley as an art gallery for the contemporary artist Wang Xiaohui (Figure 11). On the same alley, the Pingjiang Culture Centre has been created from the former Zhaoqing Temple and the Quanjin Guild House at 14 Zhangjia Alley, built in 1879, has been converted into the Museum of Kunqu Opera (Figure 12). The success of these and other adaptive reuse projects has again demonstrated the inherent adaptable characteristics of the indigenous courtyard house.

One critical approach that demarcates Pingjiang Street from many other urban regeneration projects that are solely tourist oriented is the inclusion and integration of local residents. Indeed, following numerous urban renewal projects in China that have completely removed local residents, it is admirable to see the effort to recognise the importance of and to preserve local living patterns in the Pingjiang district. Significantly, and uniquely for conservation and revitalisation projects in China, interviews were conducted, as part of the planning process, with senior residents and "...the responses of 
these residents constituted a tremendous contribution to conserving the intangible cultural heritage of the block." (UNESCO, 2005). Gong (2010: 48) also portrays how the local residents' deep emotional attachment to the neighbourhood was represented in the project. As a result, the revitalised Pingjiang historical district has retained 50 per cent of the local residents and managed to renovate 80 per cent of the original houses as it strove to respect the historical origin as a residential quarter (Ruan and Liu, 1999). However, it could be argued that this planning precept and its implementation has discouraged social mobility as most of the current residents are restrained by their economic standing. The majority of residents signed three year renewable leaseholds from the local government at an extremely low rent (approximately $\$ 6$ per year for 50 square metres) after the renovation of the houses to achieve a basic standard of modern living (Gong, 2010: 48). One significant issue is that there remains uncertainty as to whether the offspring of the current inhabitants will still be eligible by law to continue the leasehold and whether the leasehold can be inherited. Indeed, the second generation of the local inhabitants is unlikely to live there and most middle-aged and young residents have already moved out to typical middle-class residential enclaves. A recent phenomenon is also that there are many migrants from either rural villages or other comparatively poor regions illegally sub-leasing the homes from the locals. A question therefore remains as to whether the apparent inflexible residential leasing policies can create a resilient and sustainable population or whether they cause a short-term static and sterile community?

After the completion of phase one of the project in 2004, there has been no further action and the funding from the local government mainly covered the outer appearance of the streets and was insufficient for the revitalisation of the whole project. The private owners and the leaseholders were therefore responsible for the internal renewal of the existing buildings (Ruan and Liu, 1999). However, there have been a number of other experiments for renewing Suzhou's traditional courtyard houses, since the late 1980s, which have provided a model for the later revitalisation in Pingjiang district. Indeed, some courtyard houses occupied by multiple families were selectively chosen for re-planning and renovation, with the principle of protecting the function of domestic living whilst improving the existing architectural appearance. The courtyard house at 50 Shizi Street preserved from the late Qing dynasty, for example, was converted into apartments. Qu et al. (1990) note how this house was previously a public leasehold dwelling after the private housing reform in the 1950s and occupied by 17 households of 55 people before the renovation was completed in 1989. Significant improvements were made to the physical condition of the house, as well as the layout of each housing unit, which was changed from the interrelated and undifferentiated rooms into independent apartments, including the addition of an individual kitchen and bathroom for each unit. The common areas and circulation spaces were also optimised to create private access to the different units (see figure 13). The dwellings that were created proved attractive to many local residents who were living in other historical sectors of the city and wished that their residences would be renovated in the same way (Qu et al., 1990). This renovation project therefore offered a development model for other historic courtyard houses in Suzhou. Unfortunately, however, the physical condition of the project has recently deteriorated due to poor maintenance and different households have chaotically divided the internal courtyards with the public areas appropriated as storage spaces (see figures 14 and 15). It is clear, therefore, that if such projects are to provide the solution to the conservation 
of the unique courtyard homes that a planned management and maintenance programme needs to be in place from the outset.

\section{Pingjiang: Successes, Failures and Futures}

Pingjiang Street is one of numerous urban conservation and revitalisation projects all over China that showcase traditional Chinese urban townscapes. These historic legacies are intimately human and characteristically old, contrasting markedly with the highly modernised urban forms that have appeared as a result of urbanisation in Chinese cities over the past 25 years. If the modern practice of heritage projects is, as Harrison (2013: 23-28) has discussed, a critical response towards the crisis of modernity, then Pingjiang district, through consolidating an 'authentic' picture of traditional architecture and townscape, suggests that anti-growth is another valuable pathway for the life of China's urban heritage. It could be argued, however, that despite its achievements that the resurrected townscape of Pingjiang district lacks solid ideological and institutional support and is nonetheless akin to many tourist-oriented urban developments in China, becoming an 'architecture of display'. The question remains as to which is more authentic regarding the living patterns that are embodied in the courtyard houses and the streets: one is private and gentrified living in the Imperial period; the other is socialist housing shared by multiple and lower classes in the modern times.

As with urban conservationsits, the challenges of authenticity have also obsessed many historians, in their treatment of history, whether as facts of matter or as a narrative of those facts. Certainly, as Trouillot (1995:146) suggests: “...the value of a historical product ...cannot be debated without taking into account both the context of its production and the context of its consumption." The Pingiiang case study illustrates how this seems to be inextricably bound up with the vexed question of conserving and revitalising historic values in urban regeneration projects. Indeed, authenticity is embodied in our relationship to the past and yet our position towards the past varies. Trouillot (1995: 149) further highlights this by emphasising the need to underline the purpose of the interpretation, weighting this towards those serving a higher morality and that "...authenticity is required, lest the representation becomes a fake, a morally repugnant spectacle."

In relation to the conservation of China's historic townscapes an approach akin to many urban morphologists (Whitehand \& Gu, 2007; Whitehand et al., 2011) would enable a better understanding of the evolutionary processes upon urban patterns over time. This would enable urban townscape management supported by an understanding of changes to historic urban quarters and the identification and interpretation of character areas and townscape typologies. In the UK, Historic England (u.d.) advocates a comprehensive and systematic approach termed 'historic characterisation', which integrates archaeological and historical methods, in identifying and describing essential or distinguishing landscape patterns, features and qualities, or attributes. Applying such an approach in China should, however, take into account that the evolution of urban heritage in Europe has been somewhat different to that experienced in China as it moved from an imperial to socialist society. 
As such, in Pingjiang, a critical question in relation to authenticity is to how to respond to the socio-cultural authenticity of the living patterns and their associated physical forms (i.e. the courtyard houses and the streets) between the two fundamentally different historic periods in Suzhou. Indeed, the continuity of the urban fabric in Pingjiang during the Imperial period is typified by the prevalence of Confucianism and formed a richly textured community life that has left traces that can assist with the creation of a social and culturally sustainable future for the district. Indeed, courtyard houses, as an urban settlement pattern, dominated Imperial China for almost three thousand years with their longevity demonstrating a perfect unity of social life and physical form. The socialist reform of the courtyard houses, however, was a political violation of the private ownership of these properties with a short and relatively recent history (from the 1950s to the present). Indeed, this was a violent and rapid reaction to housing shortages with the merits of the re-appropriation as socialist courtyard houses still awaiting history's judgement in terms of its success.

Despite commercial gains and although marked as an important historical and cultural site, the current physical fabric of the Pingjiang fails to reflect such exalted social values that is exercised and sustained by the daily practice. Nor is there any social ideology embodied by physical form after more than one hundred years of trauma, which could be upheld by the whole of society concordantly, devotionally and inspirationally, as Confucianism was in the past. As such, the rich 'story-scape' of Pingjiang delivers lessons and indeed raises many further questions that can contribute greatly to the development of urban conservation research and practice particularly in relation to China's urban heritage. Therefore, if we demand a socially and culturally-rooted response towards urban heritage conservation, then the identification or evocation of strong socio-cultural foundations is a precondition.

\section{References}

Berliner, N. (2005) Sheltering the Past: the Preservation of China's Old Dwellings, in: House Home Family: Living and Being Chinese, ed. Ronald G. Knapp \& Kai-Yin Lo, 205-220.

Bray, F. (1997) Technology and Gender: Fabrics of Power in Late Imperial China. Berkeley: University of California Press.

Chen, F. and Thwaites, K. (2013) Chinese Urban Design: A Typomorphological Approach, Farnham: Ashgate Publishing.

College of Architecture \& Urban Planning Tongji University (ed.) (2010) Urban Heritage Conservation, Beijing: China Architecture \& Building Press.

Dai, J., Hou, X.M., Chen, Z., and Dong, M. J. (2006) The Revelation of the British and French Historic Environment Protection Regulation, in: Collection of International Symposium on Conservation of Historical Cities and Buildings, 61-63.

Dong, S.Q. (2004). From “Double Chess-board" to Pingjiang Historical Block,. in: Ancient City of Suzhou Pingjiang Historical Street/District, edited by Yuan Yixin. Shanghai: Shanghai Sanlian.

Fan, C. D. (1999) Wujun zhi. Nanjing: Jiangsu Ancient Literature Press.

Fan, L. (2014) International influence and local response: understanding community involvement in urban heritage conservation in China, International Journal of Heritage Studies, 20:6, 651-662. 
Fang, X. Q. (ed.), (2004) District and Ancient Aroma and Modern Atmosphere of Pingjiang Street, Nanjing: Jiangsu Literature and Art Publishing House.

Gong, H. (2010) "The Old Suzhounese" Time on Pingjiang Street, China Today, June: 48-49.

Gu, Z. T. (1999) Wumen biaoyin. Nanjing: Jiangsu Ancient Literature.

Harrison, R. (2013) Heritage: Critical Approaches, London: Routledge.

Historic England (undated), Historic Landscape Characterisation. Accessed 15th December, 2015,

https://www.historicengland.org.uk/research/approaches/research-

methods/characterisation-2/.

ICOMOS China (2002) Principles for the Conservation of Heritage Sites in China. Issued by China ICOMOS, Approved by the State Administration of Cultural Heritage. Translated by Neville Agnew and Martha Demas. First printed in 2002, second printing with revision. Los Angeles, CA: Ventura Printing, 2004.

ICOMOS (2003) Hoi An Declaration of Historic Districts of Asia, UNESCO Convention for the Safeguarding of the Intangible Cultural Heritage, 13-15 September, Hoi An, Vietnam.

ICOMOS (2005) Xian Declaration on the Setting of Heritage Structures, Sites and Areas, $15^{\text {th }}$ General Assembly of ICOMOS, 21 $1^{\text {st }}$ October. Accessed 8th January 2016, http://www.icomos.org/charters/xian-declaration.pdf.

Japan Agency for Cultural Affairs, UNESCO, ICCROM and ICOMOS (1994) The NARA Document of Authenticity, Nara, Japan. Accessed 8th January, 2016, http://www.icomos.org/charters/nara-e.pdf.

Jervis, N. (2005) The Meaning of Jia: An Introduction, in: House, Home, Family: Living and Being Chinese, edited by Ronald G. Kanpp and Kai-Yin Lo. Honolulu: University of Hawaii Press.

Johnston, S. (1983) The Ancient City of Suzhou: Town Planning in the Sung Dynasty, The Town Planning Review 54 (2): 194-222.

Kaufman, N. (2009) Place, Race, and Story: Essays on the Past and Future of Historic Preservation, New York and London: Routledge.

Leng, L. M. (2013) Tranquil as Pingjiang, Prosperous as Shantang - the Famous Historical Cultural Street of China Pingjiang Street and Shantang Street, Jiangsu Urban Planning 4: 20-23.

Liu, H. and Wan, Q. (2006) Reconsidering the Conservation and Planning System for "Historic and Cultural Cities" in: Collection of International Symposium on Conservation of Historical Cities and Buildings, ed. Yang, H. X. \& Liu, X. , Changsha: The University of Hunan Press, 24-28.

Lu, G. W. (1999) Wudi ji , Nanjing: Jiangsu Ancient Literature Press.

Lu, Y. Y. (2010) Historic Preservation and the Difficulty of Authenticity, in: Urban Heritage Conservation, ed. College of Architetcure \& Urban Planning Tongji University, Beijing: China Architecture \& Building Press, 62-70.

Ma, Z. Y. (1964) [Yuan] Tianjinsha·qiusi,in: Quan Yuan sanqu, ed. Yu Shusen, Beijing: Zhonghua Shuju, 242.

Ministry of Construction (2005) Guideline for Preparing Conservation Plans for Precious Historical-Cultural Cities, Beijing: China Architecture \& Building Press.

Mote, F. W. (1973) A Millennium of Chinese Urban History: Form, Time, and Space Concepts in Soochow, The Rice University Studies 59 (4): 35-65.

Pan, Z. R. (undated but written during the Qing dynasty) Sutai milu ji, Suzhou: Xie Wenhan zhai.

Qian, F. Q. (2007) China's Burra Charter: The Formation and Implementation of the China Principles, International Journal of Heritage Studies, 13:3, 255-264. 
Qu, W. Z., Jin, J. J., and Feng. Y. S. (1990) The Renovation of the Traditional Residence at No.50 Shizi Alley Suzhou, Urban Planning 6: 7-10.

RCCHSS (2009) Renowned Chinese Cultural-Historic Street Vol.1, Renowned Chinese CulturalHistoric Street Selection Committee, Beijing: China Youth Press.

Ruan, Y. S. and Lin, L. (2010) Authenticity in Relation to the Conservation of Cultural Heritage, in: Urban Heritage Conservation, 49-61.

Ruan, Y. S. and Liu, H. (1999) An Exploration of the Strategic Thinking and Theory of Preservation Planning for the Pingjiang Historical District in Suzhou, Planners 15 (1): 47-48.

Ruan, Y. S., Li, Z., and Lin, L. (2010) Old Towns of Jiangnan: Conservation of Historical Architecture and Built Environment, Shanghai: Shanghai People's Fine Arts Publishing House.

Ruan, Y. S. (2005) The Analects of Urban Heritage Conservation, Shanghai: Kexue jishu chubanshe.

Ruan, Y. S. and Xiang, B. J. (1997) Preservation and Renewal of Traditional Living Blocks in Suzhou, Urban Planning Forum 4: 45-49.

Shao, Y. and Ruan, Y. S. (2010) Evolution and Character of the Historical and Cultural Heritage Preservation Law in France, in: Urban Heritage Conservation, 143-152.

SDFZB, (2014) A brief Account of the Colonial Area in Suzhou, in: The Selective Biographies of Suzhou, Suzhou Local Biography Editorial Committee, Accessed 8 ${ }^{\text {th }}$ August, 2014, http://www.dfzb.suzhou.gov.cn/zsbl/1721127.htm

Smith, N. (2002) New Globalism, New Urbanism: Gentrification as Global Urban Strategy, Antipode, 34:3, 427-450.

SREAB (Suzhou Real Estate Administration Bureau) (2004) Ancient Residences in Suzhou. , Shanghai: Tongji University Press.

Trouillot, M. R. (1995) Silencing the Past: Power and the Production of History, Boston: Beacon Press.

UNESCO (2005) Project Profile: 2005 Honourable Mention, Pingjiang Historic Block. Accessed 16th July, 2014. http://www.unescobkk.org/culture/wh/asia-pacific-heritageawards/previous-heritage-awards-2000-2013/2005/award-winners/2005hm2

UNESCO (2009) Hoi An Protocols for Best Conservation Practice in Asia: Professional Guidelines for Assuring and Preserving the Authenticity of Heritage Sites in the Context of the Cultures of Asia, Bangkok, Thailand. Accessed 7th January, 2016.

http://unesdoc.unesco.org/images/0018/001826/182617e.pdf

UNESCO (2011) UNESCO Recommendation on the Historic Urban Landscape. Accessed 15th December, 2015. http://whc.unesco.org/en/activities/638/

UNESCO (undated) Protecting Our Heritage and Fostering Creativity. Accessed 8th January, 2016. http://en.unesco.org/themes/protecting-our-heritage-and-fostering-creativity

Wang, A. (1986) [Ming] Gushu zhi vol.1. Taibei: Taiwan Xuesheng Shuju.

Wang, J. J. (ed.), (2003) Suzhou Old News, Suzhou: Guwuxuan Publishing House.

Wang, J. (1999) Song Pingjiang cheng Fang kao. Nanjing: Jiangsu Ancient Literature.

Wang, P. (1955) [Song] Tang Hui Yao, Beijing: Zhonghua Shuju.

Whitehand, J. W. R., \& Gu, K. (2007) Urban Conservation in China: Historical Development, Current Practice and Morphological Approach. Town Planning Review, 78, 643-670.

Whitehand, J. W. R., Gu, K., Whitehand, S. M., and Zhang, J. (2011) Urban Morphology and Conservation in China, Cities 28, 171-185.

Xia, X. M. and Ma, Y. (2009) Thoughts on Cultural Conservation in Block Conservation of Suzhou Pingjiang District, Southeast Culture 5: 22-25. 
Xiaotian (1999) The History of Suzhou: Modern Period, Suzhou: The University of Suzhou Press.

Xu, J. L., Ni, J., Yu, G. X., Lu, J. P., and Wu, B. S. (2011) Ligeng Tang: Pingjiang Lishi Jiequ Panzhai. Suzhou: Guwuxuan Publishing House.

Xu, Y. N. (2000) The Chinese City in Space and Time. Honolulu: University of Hawaii Press.

Yang, H. X. \& Liu, X. (ed.) (2006) Collection of International Symposium on Conservation of Historical Cities and Buildings, Changsha: The University of Hunan Press.

Yang, K. (1993) Research on Ancient Chinese City Systems, Shanghai: Shanghai Ancient Literature Press.

Yu, S. F. (1980) A Masterpiece of the Ancient Chinese City Planning, Jianzhu Xuebao, 1: 15-20.

Yu, S. F. (1986) The Conservation and development of the Famous City Suzhou, City Planning Review 05: 9-13.

Yuan, Y. X. (ed.), (2004) Ancient City of Suzhou Pingjiang Historical Street, Shanghai: Sanlian Shudian.

Zhai, B. Q. \& Ng, M. K. (2013) Urban Regeneration and Social Capital in China: a case study of the Drum Tower Muslim District in Xi'an, Cities, 35, 14-25.

Zhang, L. G. (2006) Some Comments in the Conservation of Historic Cities, in: Collection of International Symposium on Conservation of Historical Cities and Buildings, 67-70.

Zhang, S. \& Zhou, J. (2010) On Development of Preservation System for Modern and Contemporary Architectural Heritage, in: Urban Heritage Conservation, 136-142.

Zhang, S. (2008) An Introduction to Integrated Conservation: A Way for the Projection of Cultural Heritage and Historic Environment, Shanghai: Tongji University Press.

Zhu, Y. J. (2015) Cultural Effects of Authenticity: Contested Heritage Practices in China, International Journal of Heritage Studies, DOI: 10.1080/13527258.2014.991935 